\title{
Bir Üniversiteye Bağlı İlçedeki Sağlık Hizmetleri Meslek Yüksekokulunda Okuyan Öğrencilerin Problemlerinin Analizi
}

DOI: $10.26466 /$ opus.749235

*

Hatun Erkuran* - Birsel Canan Demirbağ **

* Öğr. Gör., Gümüşhane Üni., Kelkit Sağllk Hiz. Meslek Yüksek Okulu Gümüşhane/Türkiye E-Posta: htn erkran@hotmail.com ORCID: 0000-0002-0860-5747

** Prof. Dr., Karadeniz Teknik Üniversitesi Sağlık Bilimleri Fakültesi Trabzıon/Türkiye E-Posta: cdemirbag@gmail.com ORCID: $\underline{0000-0002-7533-7201}$

$\ddot{O} z$

Üniversite yıllarl, öğrencilerin geç ergenlik döneminden yetişkinliğe geçiş yaptıklarn gelişimsel bir süreçtir. Bu fiziksel, psikolojik, sosyal ve cinsel gelişim döneminde, gençler yavaş yavaş kendi sorumlulukların üstlenirler. Üniversite ilk kez evinden uzaklaşma deneyimi yaşayanlar için özgürlük, finansal kontrol, sosyal ilişkileri düzenleme ve yeni ortama alışma gibi güçlükleri de beraberinde getirmektedir. Araştırma, bir üniversiteye bağhl ilçedeki să̆lık hizmetleri meslek yüksekokulunda okuyan öğrencilerin problemlerinin analizi amacıyla yapılmıştır. Araştırmanın evrenini bir üniversiteye bağgl ilçedeki sağllk hizmetleri meslek yüksekokulu 2018-2019 eğitim öğretim yılında öğrenime devam eden öğrencilerin tamamı (200) oluşturmuştur. Veriler 1-31 Mayıs 2019 tarihleri arasında öğrencilerin problem alanlarını saptamaya yönelik araştırmacılar tarafından geliştirilen anket formu ile toplanmıştır. Elde edilen veriler SPSS 21.0 istatistik programı kullanılarak betimleyici ve nonparametrik istatistik yöntemler ile analiz edilmiştir. Araştırmaya katılan öğrencilerin yaş ortalaması 20,45 olarak bulunmuş, yaşanılan problem içerisinde en fazla \%83,9'u ilçede kültürel imkanlarm yetersiz, \%82,6'sı ilçede gezilecek yerlerin yok denecek kadar az olmasindan kaynakl sosyal problemler, \%72,7'si stajlarm yetersiz olduğunu, \%63,6'sı laboratuvar koşullarının yetersiz olmasından kaynaklı akademik problemler, \%73,3'ü iş bulamama kaygisindan kaynakl ekonomik problemler olduğu bulunmuştur. Araştırma bulguları sosyal olanakların merkeze göre kısıtlı olduğu ilçelerde öğrencilerin sırasıyla sosyal problemler, akademik problemler, ekonomik problemler yaşadığını ortaya koymuştur.

Anahtar Kelimeler: Üniversite, sağlık hizmetleri öğrencisi, problem analizi 


\title{
Analysis of The Problems of Students at Healthcare School of Health Services in a District Department of a University
}

\begin{abstract}
University years are a developmental process in which students transition from late adolescence to adulthood. In this period of physical, psychological, social and sexual development, young people gradually assume their responsibilities. For the first time away from home, the university brings difficulties such as freedom, financial control, regulation of social relations and getting used to the new environment. The aim of this study was to analyze the problems of students attending a vocational school of health services in a district of a university. The population of the study consisted of all (200) students attending the vocational school of health services in a district affiliated to a university in the 2018-2019 academic year. The data were collected between 1-31 May 2019 with a questionnaire developed by the researchers to determine the problem areas of the students. The data obtained were analyzed with descriptive and nonparametric statistical methods using SPSS 21.0 statistical program. The average age of the students who participated in the research was found to be $20.45, \% 83,9$ of the problems were inadequate cultural facilities in the district, \%82,6 were social problems due to the lack of places to visit in the district, \%72,7 of them were inadequate internship, \%63,6 were academic problems due to insufficient laboratory conditions, $\% 73,3$ were economic problems due to lack of employment. The results of the study revealed that students had social problems, academic problems and economic problems in the districts where social facilities were limited compared to the center.
\end{abstract}

Keywords: University, Healthcare School students, problem analysis 


\section{Giriş}

Yaşamın her döneminde o döneme bağlı farklı güçlüklerle karşılaşılmaktadır. 18 ile 33 yaşları arası çocukluk ve yetişkinlik arasında köprü olarak bilinmektedir (Rodríguez-SanzI vd., 2018). Bu dönem aynı zamanda üniversite başlangıç yaşıdır. Üniversite yılları, öğrencilerin geç ergenlik döneminden yetişkinliğe geçiş yaptıkları gelişimsel bir süreçtir (Mortier vd., 2015; Bruffaerts vd., 2018 ). Bu fiziksel, psikolojik, sosyal ve cinsel gelişim döneminde, gençler yavaş yavaş kendi sorumluluklarını üstlenirler. Ayrıca, daha fazla özerklik isteme, yaşam tarzların kontrol etme, fiziksel aktivitelerini kontrol etme ve tutum geliştirme gibi değişikliklere de maruz kalırlar (Aşcl, Hazar, Kılıç ve Korkmaz, 2015; Rodríguez-SanzI vd., 2018).

Üniversite ilk kez evinden uzaklaşma deneyimi yaşayanlar için özgürlük, finansal kontrol, sosyal ilişkileri düzenleme ve yeni ortama alışma gibi güçlükleri de beraberinde getirmektedir (Özgür, Gümüş ve Durdu, 2010; Metzger vd., 2017; Kronfol vd., 2018; Perera ve Abeysena, 2018; Taremian vd., 2018). Yüksek öğrenim kurumlarının öğrencileri, çoklu sosyo-kültürel temelleri olan insanlardır, özellikle ilk yıl boyunca, sadece akademik yükü değil aynı zamanda zihinsel sağlık sorunların tetikleme veya kötüleştirme, ebeveyn evini terk etmek, duygusal izolasyon, çevresel değişimler, finansal sıkıntı ve gelecekle ilgili endişeler yaşarlar (Tavolacci vd., 2013; Güngörmüş, Okanlı ve Kocabeyoğlu, 2015; Torres vd., 2017; Russell, Almedia ve Maggs, 2017; Yi, Peltzer ve Pengpid, 2017; Kebede, Molla ve Gerensea, 2018).

Geleceğin profesyonelleri, kıdemli yöneticileri ve politikacıları olabilecek bu nüfus grubunun sağlığı ve iyiliği yalnızca potansiyel toplumsal etkilerinden dolayı değil, yaşam tarzıyla ilgili birçok tutum ve alışkanlıklarının bu aşamada oluştuğu ve yaşam boyu devam ettiği için önemlidir ( Hussain, Guppy, Robertson ve Temple, 2013). Başarı için bir üniversite diploması almak anahtar olarak görülmektedir. Öğrencilerden bu dönemde hem başarılı olması hem de yetişkin gibi davranması beklenmektedir ( Beiter vd., 2015; Aydın, 2017). Bu beklentilerin yanı sıra akademik gereksinimler, kariyer kararları, yeni bir ortama uyum sağlama, kişisel ilişkiler, barınma ihtiyacl, yorucu müfredat ve değerlendirmeye tabi olmak zorunda olmak üniversite öğrencileri için birçok duygusal strese yol açabilmektedir (Özer, 2016; Azad, Shahid, Abbas, Shaheen ve Munir, 2017; Jun ve Lee, 2017; Wallace, Boynton ve Lytle, 2017; Özhan ve Boyac1 2018). 
Ülkemizde Siyaset, Ekonomi ve Toplum Araştırmaları Dergisinin 2011 yılında hazırladığı SETA raporu "YÖK'ün 30 yılı"na göre 1974-1981 yılları arasında 9 devlet, 19 vakıf üniversitesi kurulmuş, 2006 yılından itibaren “her ile bir üniversite" yaklaşımı ile üniversitesi olmayan ilimiz kalmamıştır ( Gür ve Çelik 2011). YÖK 2019 verilerine göre Türkiye' de 129 devlet, 73 vakıf ve 5 vakıf MYO olmak üzere toplam 207 üniversite bulunmaktadır. Artan üniversite sayısı ülkemizde üniversite de okuyan öğrenci sayısını da artırmıştır. 2013-2014 eğitim-öğretim yılında üniversitede okuyan toplam öğrenci sayısı 2508079 iken bu sayı 2018-2019 eğitim-öğretim yılında 7740502'ye yükselmiştir ( Gizir, 2005; yök.gov.tr). Her yıl artan öğrenci sayısı öğrencilerin problemlerini de artırmış ancak öğrencilerin problemlerini belirlemek için yapılan çalışmalar il merkezlerinde okuyan öğrenciler üzerinde yoğunlaşmıştır ( Gizir, 2005; Pektaş ve Bilge 2007; Özkan ve Yılmaz 2010; Kacur ve Atak 2011; Erkan, Özbay, Cihangir-Çankaya ve Terzi, 2012; Topkaya ve Meydan 2013; Kiraz, 2015; Aydın ve Egemberdiyeva, 2018). İlçelerde üniversitenin sosyal tesisleri, ulaşım, üniversite kampüsü, kampüs içi etkinlik olanakları yeterli olmamakla birlikte öğrencilerin beklentilerini karşılayamamaktadır.

Bu doğrultudan hareketle yola çıkılan bu çalışma da bir üniversiteye bağlı ilçedeki sağlık hizmetleri meslek yüksekokulunda okuyan öğrencilerin problemlerinin analizi yapılmıştır.

\section{Yöntem}

Bir üniversiteye bağlı ilçedeki sağlık hizmetleri meslek yüksekokulunda okuyan öğrencilerin problemlerini değerlendirmek amacıyla yapılan bu araştırma tanımlayıcı tipte bir araştırmadır. 2018-2019 eğitim öğretim yılında Gümüşhane Üniversitesi Kelkit Sağlık Hizmetleri Meslek Yüksekokulu Tıbbi Hizmetler ve Teknikler Bölümü İlk ve Acil Yardım Programında kayıtlı 200 öğrenci araştırmanın evrenini oluşturmaktadır. Anketler, 2018-2019 eğitim öğretim yılı bahar döneminde 01-31 Mayıs tarihleri arasında araştırmacılar tarafından öğrencilere uygulanmıştır. Araştırmanın yapıldığı tarihlerde okulda bulunup araştırmaya katılmayı kabul eden 165 öğrenci (evrenin \%82,5'i) araştırmanın örneklemini oluşturmuştur. Bu çalışmanın yürütülebilmesi için Gümüşhane Üniversitesi Rektörlüğü Etik Kurulundan onay alınmıştır. 
Araştırmacılar tarafından ilgili literatür taraması yapılarak konu ile ilgili bilgiler toplanmıştır. Toplanan bilgiler ışığında öğrencilerin yaşadıkları problemler "Fiziksel Problemler", "Akademik Problemler", "Ekonomik Problemler", "Sosyal Problemler" ve "Duygusal Problemler" olarak 5 ana kategoriye ayrilmıştır. Ankette bulunan Fiziksel Problemler 7, Akademik Problemler 22, Ekonomik Problemler 9, Sosyal Problemler 15, Duygusal Problemler 12 maddeden oluşmaktadır ve öğrencilerden problem yaşadıkları alt maddeleri işaretlemeleri istenmiştir.

Araştırma sonucunda elde edilen veriler SPSS 21.0 istatistik programı kullanılarak analiz edilmiştir. Verilerin analizinde betimleyici ve nonparametrik istatistik yöntemlerden yararlanılmıştır. Her bir problem için sıklık ve yüzdelikler belirlenmiştir.

\section{Bulgular}

Araştırmaya katılan öğrencilerin yaş aralığı minimum 18, maksimum 24, yaş ortalaması 20,45 olarak bulunmuştur. Öğrencilerin \%39,4'ü 20 yaşında, $\% 23,6$ 'sı 21 yaşındadır.

Tablo 1. Öğrencilerin Cinsiyet, Sınıf, Yaşanılan Yer Dağılımlar

\begin{tabular}{llll}
\hline Değişkenler & & N & \% \\
\hline \multirow{3}{*}{ Cinsiyet } & Kadın & 96 & 58,2 \\
\hline \multirow{3}{*}{ Sınıf } & Erkek & 69 & 41,8 \\
\hline \multirow{4}{*}{ Yaşanılan Yer } & 1.Sınıf & 93 & 56,4 \\
& 2. Sınıf & 72 & 43,6 \\
\hline & Aile ile & 7 & 4,2 \\
& Yurtta & 132 & 80,0 \\
& Akraba/Arkadaş & 10 & 6,1 \\
& Kendi Başına Evde & 16 & 9,7 \\
\hline
\end{tabular}

Araştırmaya katılan öğrencilerin \%58,2'si kadın, \%56,4'ü 1.sınıfta okumakta ve \%80,0'1 yurtta yaşamaktadır (Tablo 1).

Gümüşhane Üniversitesi Kelkit Sağllk Hizmetleri Meslek Yüksekokulu öğrencilerinin problem alanları ile ilgili elde edilen bulgular 5 ana başlık altında kategoriler halinde sunulmuştur.

Tablo 2. Öğrencilerin Problem Yaşadıklan Alanların Dă̆ılımlan

\begin{tabular}{lll}
\hline Problemler & Frekans & Yüzde \\
\hline Fiziksel Problemler* & & \\
\hline
\end{tabular}


Bir Üniversiteye Bağlı İlçedeki Sağlık Hizmetleri Meslek Yüksekokulunda Okuyan Öğrencilerin Problemlerinin Analizi

\begin{tabular}{|c|c|c|}
\hline Kronik bir hastalığım var & 7 & 5,8 \\
\hline İştahsızım & 24 & 19,8 \\
\hline İyi beslenemiyorum & 65 & 53,7 \\
\hline Fiziksel görünüşümü beğenmiyorum & 15 & 12,4 \\
\hline Sık sık başım ağrıyor & 41 & 33,9 \\
\hline Sık sık grip- nezle oluyorum & 27 & 22,3 \\
\hline Çok terliyorum & 21 & 17,4 \\
\hline \multicolumn{3}{|l|}{ Akademik Problemler* } \\
\hline Aile, arkadaş ve öğretmenlerim istediği için bu bölümü tercih ettim & 23 & 13,9 \\
\hline Puanım bu bölümü tuttuğu için bu bölümü tercih ettim & 56 & 33,9 \\
\hline İş bulma sorunu olmadığı için bu bölümü tercih ettim & 50 & 30,3 \\
\hline Derslerde teorik bilgi çok fazla & 40 & 24,2 \\
\hline Dersler çok zor, ezberlemek zorunda kalıyorum & 47 & 28,5 \\
\hline Mesleğe yönelik olmayan dersler işleniyor & 61 & 37,0 \\
\hline Aşırı ders yükü mevcut & 31 & 18,8 \\
\hline Bazı dersler yüzeysel işleniyor & 32 & 19,4 \\
\hline Yeterli uygulama yapma imkanı yok & 77 & 46,7 \\
\hline Laboratuvar koşulları yetersiz & 105 & 63,6 \\
\hline Stajlar yetersiz & 120 & 72,7 \\
\hline Sevmediğim dersleri okumaya zorlanıyorum & 34 & 20,6 \\
\hline Derslerin belirli bir kitabı, ders notu ve kaynak kitabı yok & 70 & 42,4 \\
\hline Haftalık ders dağılım programları iyi ayarlanmıyor & 45 & 27,3 \\
\hline Derslerin Öğretim Elemanları ile iletişim sıkıntısı yaşıyorum & 2 & 1,2 \\
\hline Yeterli mesleki formasyona sahip olmama kaygısı yaşıyorum & 31 & 18,9 \\
\hline Mezuniyet sonrası ne yapacağını bilemiyorum & 70 & 42,7 \\
\hline Okuduğum bölümden menün değilim & 9 & 5,5 \\
\hline Verimli ders çalışmakta güçlük çekiyorum & 54 & 32,9 \\
\hline Ders çalışma salonlarında güçlükle çalışıyorum & 24 & 14,6 \\
\hline Zaman zaman sinavlarda kopya çekmek zorunda kalıyorum & 20 & 12,2 \\
\hline Okulda problemlerim hakkında başvurabileceğim kimse yok & 13 & 7,9 \\
\hline \multicolumn{3}{|l|}{ Ekonomik Problemler* } \\
\hline Ev kirası/ yurt ücretinin ödemekte zorluk yaşıyorum & 61 & 40,7 \\
\hline Günlük besin ihtiyacının karşılanmasında zorluk yaşıyorum & 41 & 27,3 \\
\hline Giyim ihtiyaçların karşılanmasında zorluk yaşıyorum & 31 & 20,7 \\
\hline Ulaşım ücretini karşılanmada zorluk yaşıyorum & 30 & 20,0 \\
\hline Kırtasiye ders araç-gereç, fotokopi vb. ihtiyaçların karşlanmasında sorun & 19 & 12,7 \\
\hline yaşıyorum & 30 & 20,0 \\
\hline Harç kredisinin ödenmesinde sorun yaşıyorum & 110 & 73,3 \\
\hline İş bulamama kaygısı yaşıyorum & 66 & 44,0 \\
\hline Lokantalarda yemek ücretleri pahalı & 78 & 52,0 \\
\hline \multicolumn{3}{|l|}{ Okul/ yurt yemekhanesinde ücretler fazla } \\
\hline \multicolumn{3}{|l|}{ Sosyal Problemler* } \\
\hline Sosyal ve kültürel etkinliklere katılmada sorun yaşıyorum & 33 & 20,5 \\
\hline Derslerin yoğunluğundan kaynaklanan zaman yetersizliği yaşıyorum & 32 & 19,9 \\
\hline Spor tesislerinin ve aktiviteleri yetersiz & 96 & 59,6 \\
\hline Aktiviteler yeterince duyurulmuyor & 89 & 55,3 \\
\hline İlçedeki kültürel imkanlar (tiyatro, sinema vs) yetersizdir & 135 & 83,9 \\
\hline İlçede yaşamaktan dolayı mutsuzum & 96 & 59,6 \\
\hline \multirow[t]{2}{*}{ İlçedeki esnafın, halkın öğrencilere karşı tutum ve davranışları iyi değildir } & 93 & 57,8 \\
\hline & 41 & 25,5 \\
\hline
\end{tabular}




\begin{tabular}{lll}
\hline Ev, yurt sahiplerinin /yöneticilerinin öğrencilere yönelik tutum ve davranış- & 40 & 24,8 \\
ları iyi değildir & 80 & 49,7 \\
İlçe olması nedeniyle istediğim gibi giyinme problemi yaşıyorum & 46 & 28,6 \\
Havaların sürekli soğuk olmasından dolayı sorun yaşıyorum & 97 & 60,2 \\
İlçeye ulaşım imkanı kısıtlı & 133 & 82,6 \\
Cafe, lokanta gibi olanaklar kısıtlı & 56 & 34,8 \\
Gezilebilecek yerler yok denecek kadar az & 63 & 39,1 \\
Kız- erkek karışı gidilebilecek mekanlar kısıtlı & & \\
İlçe olması nedeniyle istediğim gibi davranma/yaşama problemleri & & \\
\hline Duygusal Problemler* & & \\
\hline İnsanlarla iletişimde sıkıntı yaşıyorum & 19 & 13,0 \\
Okul arkadaşlarılyla sorun yaşıyorum & 20 & 13,7 \\
Karşı cinsle olan arkadaşlık ilişkilerinde sorun yaşıyorum & 13 & 8,9 \\
Arkadaşlı ilişkilerinin çok yüzeysel olduğunu düşünüyorum & 50 & 34,2 \\
İnsanlara güvenemiyorum & 88 & 60,3 \\
Arkadaşlı ilişkileri çkara dayalı olduğunu düşünüyorum & 80 & 54,8 \\
Ailemi özlüyorum & 80 & 54,8 \\
Ailemin yanında olmak istiyorum & 65 & 44,5 \\
Başkalarıyla tanışmakta güçlük çekiyorum & 8 & 5,5 \\
Kendimi aşırı mutsuz hissediyorum & 38 & 26,0 \\
Kız erkek arkadaşlı̆ğı bulunduğum ilçede hoş karşılanmıyor & 56 & 38,4 \\
Kız/erkek arkadaşıla elele gezdiğimde insanların bakışlarından rahatsız & 42 & 28,8 \\
oluyorum & & \\
\hline
\end{tabular}

*Sadece evet cevabı verenler alındı

Öğrencilerin fiziksel problemleri incelendiğinde \%53,7'sinin iyi beslenemediğini, \%33,9'unun sık sık baş ağrısı yaşadığını belirtmiş, akademik problemlerinde $\% 72,7^{\prime}$ si stajların yetersiz olduğunu, \%63,6'sı laboratuvar koşullarının yetersiz olduğunu belirtmiştir. Ekonomik problemlerinde $\% 73,3^{\prime}$ ü iş bulamama kaygisı yaşadığı, \% 52,0'1 okul/yurt yemekhanelerinde ücretlerin fazla olduğunu belirtmiştir. Öğrencilerin sosyal problemleri içerisinde $\% 83,9^{\prime}$ u ilçede kültürel imkanların yetersiz olduğu, \%82,6'sı ilçede gezilecek yerlerin yok denecek kadar az olduğu, \%60,2'si cafe, lokanta gibi olanakların kısıtlı olduğu bulunmuş, duygusal problemler içerisinde \%60,3'ü insanlara güvenemediğini, $\% 54,8^{\prime}$ i arkadaşlık ilişkilerinin çıkara dayalı olduğunu belirtmiştir (Tablo 2).

\section{Tartışma ve Sonuç}


Üniversite eğitiminin başlaması ile öğrencilerin aile ortamından ayrılması, ekonomik, sosyal, akademik, kültürel, meslek edinme ve boş zamanının değerlendirme gibi birçok sorunla karşılaşmaktadırlar. Bir üniversiteye bağlı ilçedeki sağlık hizmetleri meslek yüksekokulunda okuyan öğrencilerin problemlerinin belirlenmesi amacıyla yapılan bu çalışmada; araştırmaya katılan öğrencilerin \%39,4'ü 20 yaşında, \%58,2'si kadın, \%56,4'ü 1.sınıfa devam etmektedir (Tablo 1). Araştırmanın örneklemi üniversite öğrencileri ile yapılan diğer çalışmalarla benzerlik göstermektedir ( Özkan ve Yılmaz 2010; Kacur ve Atak 2011; Doğan ve Eser 2013).

Araştırmada öğrencilerin \%53,7'si fiziksel problem olarak iyi beslenemediğini belirtmiştir. Yılmaz ve Özkan'ın (2007) üniversite öğrencilerinin beslenme alışkanlıklarını inceledikleri çalışmada öğrencilerin \%90,3'ünün öğün atladığı ve en fazla atlanan öğünün zaman bulamamaktan kaynaklı olarak öğle yemeği olduğu bulunmuştur. Bu araştırmada öğrencilerin \%80'i yurtta kalmaktadır. Araştırmanın yapıldığı ilçede özel yurt bulunmadığı için kalınan yurt Kredi Yurtlar Kurumuna bağlıdır. Öğrencilerin büyük çoğunluğunun yurtta kaldığ ve $\% 52$ 'sini okul/yurt yemekhanelerinde yemek ücretlerinin pahalı olduğunu belirttiği göz önüne alındığında problemin maddi durumdan kaynaklı olduğu düşünülebilir.

Öğrencilerin belirtmiş olduğu akademik problemler içerisinde \%72,7'si stajların yetersiz olduğunu, \%63,6'sı laboratuvar koşullarının yetersiz olduğunu bildirmişlerdir. Araştırmanın yapıldığı Yüksekokul 2008 tarihinde kurulmuş ve 2011 yılında öğrenci alımına başlamıştır. Öğrenciler Mesleki Uygulama dersi ile Kelkit İlçe Devlet Hastanesi Acil Servisine staja gönderilmektedir ancak Yüksekokul öğrencilerine hastane tarafından staj ücreti ödenmesi ve hastane kapasitesinin az olması nedeniyle tüm öğrenciler staja kabul edilmemektedir. Bu durum göz önüne alındığında sonucun bu şekilde çıkması beklenen bir durumdur. Öğrencilerin \% 33,9'u puanı bu bölümü tuttuğu için bölümü tercih ettiğini \%30,3'ünün iş bulma sorunu olmadığ için bu bölümü tercih ettiklerini belirtmiştir. Bu araştırmaya benzer şekilde Özkan ve Yılmaz (2010)'ın üniversite öğrencilerinin üniversite yaşamına uyum durumlarını araştırdıkları çalışmada; öğrencilerin \%31,1'inin puanı okuduğu bölümü tutması nedeniyle bölümü tercih ettiklerini bulmuşlardır.

Ekonomik problemler içerisinde öğrencilerin \%40,7'si ev kirasi/yurt ücretini karşılamada güçlük çektiğini, \%27,3'ünün günlük besin ihtiyacını karşılamada sorun yaşadığı bulunmuştur. Araştırma sonuçlarına benzer 
şekilde, Özkan ve Yılmaz'ın (2010) yaptıkları araştırmada öğrencilerin $\% 41,7^{\prime}$ si ev kirasi/yurt ücretinin ödenmesinde, \%32,8'i günlük besin ihtiyacını karşılamada zorluk yaşadığını bulmuşlardır.

$\mathrm{Bu}$ araştırmada öğrencilerin $\% 53,3^{\prime}$ ü iş bulamama kaygısı yaşadığını belirtmiştir. Araştırma bulgularından farklı olarak Gizir 2005 yılında ODTÜ öğrencileri ile yaptığı çalışmasında öğrencilerin \%29,4'ünün iş bulamama kaygısı yaşadığını bulmuştur. ODTÜ gibi köklü ve Türkiye'nin önde gelen üniversitelerinden birinde öğrencilerin iş bulma kaygısının da yüksek olması düşündürücüdür. Türkiye'nin ekonomik ve sosyal durumu, öğrencilerin KPSS sınavına hazırlanmak ve yüksek puan almak gerekliliği, üniversite mezunu işsiz oranındaki artş düşünüldüğünde öğrencilerin bu tür kaygılar yaşamaları anlaşılabilmektedir.

Araştırmada öğrencilerin \%82,6'sı ilçede gezilecek yerler olmadığını, $\% 60,2^{\prime}$ si cafe, lokanta gibi olanakların kısıtlı olduğunu, \%83,9'u ilçede kültürel imkanların yetersiz olduğunu belirtmiştir. Araştırma sonuçlarına benzer şekilde Kiraz'ın 2015 yılında Tokat ilinde üniversite öğrencilerinin sorunlarının belirlemek için yaptığı çalışmasında öğrencilerin bulundukları kentte gezilecek yerler olmaması, sosyal imkanların yetersiz olması, vakit geçirilecek yerlerin az olması konularında sıkıntılar yaşadığı bulunmuştur. Bu sonuç üniversitelerin farklı sosyal imkanlara ve olanaklara sahip olmasından kaynaklandığı gibi, çalışma grubunun şehir ve ilçede olması, yeni kurulan üniversite olması nedeniyle daha kısıtlı imkanlara sahip olmasından kaynaklanabilir.

Araştırmaya katılan öğrencilerin duygusal problemleri içerisinde en çok sorun yaşadığ daşlık ilişkilerinin çıkara dayalı olduğu ve ailelerini özledikleri bulunmuştur. Aş̧̧ı ve arkadaşlarının 2015 yılında yaptıkları çalışmada \%90,5 oranında ilişkilerin çıkara dayalı olduğunu, Gizir' in (2005) araştırmasında ise \%24,1 oranında ilişkilerin çıkara dayalı olduğunu bulmuşlardır. Bulunan sonuçlar arasında bu kadar fark olması öğrencilerin içinde bulunduğu gelişimsel dönemden kaynaklı olduğu düşünülebilir. Gençlerin kendini tanımaması, kimlik bunalımı içinde olması insanları tanımayı engelleyebilmekte, önyargılara sebep olabilmektedir.

$\mathrm{Bu}$ araştırmanın tek bir üniversiteye bağlı bir ilçede yapılmış olması araştırmanın sınırlılıklarındandır. Bundan sonraki araştırmalarda farklı 
üniversitelerin farklı ilçelerinde öğrenim gören üniversite öğrencilerine ulaşılmasının faydalı olacağı kanısındayız.

Sonuç olarak; sosyal olanakların merkeze göre kısıtlı olduğu ilçelerde öğrencilerin hangi sorunları daha sık yaşadığını belirlemek için gerçekleştirilen bu araştırmanın konuyla ilgilenen uygulayıcılara yol gösterici olacağı düşünülmektedir. Ergenlikten genç yetişkinliğe geçiş dönemi olan üniversite yılları toplumda sağlıklı yetişkinler olabilmesi açısından üzerinde önemle durulması gereken yıllardandır. Öğrenciler bu dönemde kendi kimliğini bulma çabası, üniversite ortamına uyum sağlama, duygusal, ekonomik, sosyal ve akademik problemler yaşamaktadırlar. Üniversite kampüslerinde sunulan Psikolojik Danışma ve Rehberlik hizmetlerinin merkez kampüse bağımlı kalmayıp ilçeleri de kapsayarak ilçedeki öğrencilerinde bu hizmetlerden yararlanması sağlanmalıdır. 


\title{
Analysis of The Problems of Students at Healthcare School of Health Services in a District Department of a University
}

\author{
Hatun Erkuran, Birsel Canan Demirbağ \\ Gümüşhane University, Karadeniz Technic University
}

University years are a developmental process in which students transition from late adolescence to adulthood. In this period of physical, psychological, social and sexual development, young people gradually assume their responsibilities. For the first time away from home, the university brings difficulties such as freedom, financial control, regulation of social relations and getting used to the new environment. Students of higher education institutions are people with multiple socio-cultural backgrounds, especially during the first year, they experience not only academic burden but also triggering or worsening mental health problems, leaving parental home, emotional isolation, environmental changes, financial distress and worries about the future. The health and well-being of this population group, which may be future professionals, senior managers and politicians, is important not only because of its potential social impacts, but also because many attitudes and habits related to lifestyle are formed at this stage and continue throughout life. Getting a university degree is seen as the key to success. Students are expected to be both successful and behave like an adult during this period. In addition to these expectations, academic needs, career decisions, adaptation to a new environment, personal relationships, need for housing, tiring curriculum and being subject to evaluation can cause many emotional stresses for university students.

The increasing number of students every year has also increased the problems of the students, but the studies carried out to determine the problems of the students have concentrated on the students studying in the provincial centers. Although the social facilities of the university, transportation, university campus and on-campus activity opportunities are not sufficient in the districts, they cannot meet the expectations of the students. The aim of this study was to analyze the problems of students attending a vocational school of health services in a district of a university. 
The population of the study consisted of all (200) students attending the vocational school of health services in a district affiliated to a university in the 2018-2019 academic year 165 students who were at the school at the time of the study and agreed to participate in the study constituted the sample of the study.. The relevant literature was searched by the researchers and information on the subject was collected. In the light of the information gathered, the problems experienced by the students were divided into 5 main categories as "Physical Problems", "Academic Problems", "Economic Problems", "Social Problems" and "Emotional Problems". The questionnaire consists of 7 Physical Problems, 22 Academic Problems, 9 Economic Problems, 15 Social Problems, and Emotional Problems 12 items, and the students were asked to mark the sub-items they had problems with. The data were collected between 1-31 May 2019 with a questionnaire developed by the researchers to determine the problem areas of the students.

The data obtained were analyzed with descriptive and nonparametric statistical methods using SPSS 21.0 statistical program. The average age of the students who participated in the research was found to be 20.45 , when the physical problems of the students were examined, $53.7 \%$ stated that they were not eating well, $33.9 \%$ had frequent headaches, $72.7 \%$ of them stated that internships were insufficient in academic problems, $63.6 \%$ stated that they had laboratory-exist conditions. stated that it was insufficient. In economic problems, $73.3 \%$ stated that they were anxious about not being able to find a job, $52.0 \%$ stated that the wages were high in the school / dormitory cafeterias. Among the social problems of the students, $83.9 \%$ of them were found to have insufficient cultural facilities in the district, $82.6 \%$ of them were found to be very few places to visit in the district, $60.2 \%$ of them were found to have limited facilities such as cafes and restaurants, emotional problems $60.3 \%$ of them stated that they could not trust people, $54.8 \%$ stated that friendship relationships are based on interests. One of the limitations of the study is that this study was conducted in a district of a single university.

The results of the study revealed that students had social problems, academic problems and economic problems in the districts where social facilities were limited compared to the center. University years, which are the transition period from adolescence to young adulthood, are the years 
that should be emphasized in terms of being healthy adults in the society. During this period, students struggle to find their own identity, adapt to the university environment, and experience emotional, economic, social and academic problems. Psychological Counseling and Guidance services offered on university campuses should not be dependent on the central campus, but should also be included in the districts and students in the district should benefit from these services.

\section{Kaynakça / References}

Aşcı, Ö., Hazar, G., Kılıç, E. ve Korkmaz, A. (2015). Üniversite Öğrencilerinde Stres Nedenlerinin ve Stresle Başa Çıkma Biçimlerinin Belirlenmesi. Uşak Üniversitesi Sosyal Bilimler Dergisi, 8(4), 213-232.

Aydın, M. (2017). Lisans Öğrencilerinin Psikolojik Yardım Aramaya Gönüllülüklerinin İncelenmesi. Ylldız Sosyal Bilimler Enstitüsü Dergisi, 1(1), 76-94.

Aydın, M. ve Egemberdiyeva, A. (2018). Üniversite Öğrencilerinin Psikolojik Sağlamlık Düzeylerinin İncelenmesi. Türkiye Ĕğitim Dergisi, 3(1), 37-53.

Azad, N., Shahid, A., Abbas, N., Shaheen, A. ve Munir, N. (2017). Frequency Of Anxiety And Depression In Medical Students Of A Private Medical College. J Ayub Med Coll Abbottabad, 29(1), 123-127

Beiter, R., Nash, R., McCrady, M., Rhoades, D., Linscomb, M., Clarahan, M. ve Sammut, S. (2015). The Prevalence And Correlates Of Depression, Anxiety, And Stress İ A Sample Of College Students. Journal of Affective Disorders, 17,390396.

Bruffaerts, R., Mortier, P., Kiekens, G., Auerbach, R. P., Cuijpers, P., Demyttenaere, K., Green, J. G., Nock, M. K. ve Kessler, R. C. (2018). Mental Health Problems In College Freshmen: Prevalence And Academic Functioning. J Affect Disord. 1(225), 97-103

Doğan, B. ve Eser, M. (2013). Üniversite Öğrencilerinin Stresle Başa Çıma Yöntemleri: Nazilli MYOÖrneği. Electronic Journal of Vocational Colleges, UMYOS Özel Sayl, 29-39.

Erkan, S., Özbay, Y., Cihangir-Çankaya, Z. ve Terzi, Ş. (2012). Üniversite Öğrencilerinin Yaşadıkları Problemler ve Psikolojik Yardım Arama Gönüllükleri. Eğitim ve Bilim, 37(164), 94-107.

Gizir, C. A. (2005). Orta Doğu Teknik Üniversitesi Son Sınıf Öğrencilerinin Problemleri Üzerine Bir Çalışma. Mersin Üniversitesi Eğitim Fakültesi Dergisi, 1(2), 196213. 
Güngörmüş, K., Okanll, A. ve Kocabeyoğlu, T. (2015). Hemşirelik Öğrencilerinin Psikolojik Dayanıklılıkları ve Etkileyen Faktörler. Journal of Psychiatric Nursing, 6(1), 9-14.

Gür, B. S. ve Çelik, Z. (2011). YÖK'ün 30 Yull. SETA Rapor, Siyaset, Ekonomi ve Toplum Araştrmaları Vakfi.

Hussain, R., Guppy, M., Robertson, S. ve Temple, E. (2013). Physical And Mental Health Perspectives Of First Year Undergraduate Rural University Students. BMC Public Health, 13(848), 2-11.

Jun, W. H. ve Lee, G. (2017). Comparing Anger, Anger Expression, Life Stress And Social Support Between Korean Female Nursing And General University Students. J Adv Nurs.73, 2914-2922.

Kacur M. ve Atak M. (2011). Üniversite Öğrencilerinin Sorun Alanları Ve Sorunlarla Başetme Yollarr: Erciyes Üniversitesi Örneği. Sosyal Bilimler Enstitüsü Dergisi, 31(2), 273-297.

Kebede A., Molla B. ve Gerensea H. (2018). Assessment Of Risky Sexual Behavior And Practice Among Aksum University Students, Shire Campus, Shire Town, Tigray, Ethiopia, 2017. BMC Res Notes,11/88.

Kiraz Z. (2015). Üniversite Öğrencilerinin Sorunları: Tokat Örneği. Akademik Sosyal Araştırmalar Dergisi, 3(9), 521-534.

Kronfol Z., Khalifa B., Khoury B., Omar O., Daouk S., deWitt J. P., ElAzab N. ve Eisenberg D. (2018). Selected Psychiatric Problems Among College Students İn Two Arab Countries: Comparison With The USA. BMC Psychiatry 18, 147.

Metzger I. W., Blevins C., Calhoun C. D., Ritchwood T. D., Gilmore1 A. K., Stewart R. ve Bountress K. E. (2017). An Examination of the Impact of Maladaptive Coping on the Association between Stressor Type and Alcohol Use in College. J Am Coll Health, 65(8), 534-541.

Mortier P., Demyttenaere K., Auerbach R. P., Green J. G., Kessler R. C., Kiekens G., Nock M. K. ve Bruffaerts R. (2015). The İmpact Of Lifetime Suicidality On Academic Performance İn College Freshmen. J Affect Disord. 186, 254-260.

Özer E. (2016). Temel Benlik Değerlendirmesi, Başa Çıkma Stratejileri Ve Psikolojik Sağlamlık. International Periodical for the Languages, Literature and History of Turkish or Turkic, 11(149), 587-606

Özgür G., Gümüş A. B. ve Durdu B. (2010) Evde ve Yurtta Kalan Üniversite Öğrencilerinde Yaşam Doyumu. Journal of Psychiatric Nurses, 1(1), 25-32.

Özhan M. B. ve Boyacı M. (2018). Üniversite Öğrencilerinde Depresyon, Anksiyete Ve Stresin Yordayıcısı Olarak Azim: Bir Yapısal Eşitlik Modellemesi. Anadolu Psikiyatri Dergisi, 19(4), 370-376. 
Özkan S. ve Yllmaz E. (2010). Üniversite Öğrencilerinin Üniversite Yaşamına Uyum Durumları (Bandırma Örneği). Fırat Sağlkk Hizmetleri Dergisi, 5(13), 153-171.

Pektaş İ. ve Bilge A. (2007). Ege Üniversitesi İzmir Atatürk Sağlık Yüksekokulu Öğrencilerinin Problem Alanlarını Belirlenmesi. İnönü Üniversitesi Ĕ̆itim Fakültesi Dergisi, 8(14), 83-98.

Perera U. A. P. ve Abeysena C. (2018). Prevalence And Associated Factors Of Risky Sexual Behaviors Among Undergraduate Students İn State Universities Of Western Province İn Sri Lanka: A Descriptive Cross Sectional Study. Reproductive Health 15, 105.

Rodríguez-SanzI D., Barbeito-Fernández D., Losa-Iglesias M. E., Saleta-Canosa J. L., López-López D. , Tovaruela-Carrión N. ve Becerro-de-Bengoa-Vallejo R. (2018). Foot Health And Quality Of Life Among University Students: CrossSectional Study. Sao Paulo Med J. 136(2), 123-8.

Russell M. A., Almeida D. M. ve Maggs J. L. (2017). Stressor-Related Drinking and Future Alcohol Problems among University Students. Psychol Addict Behav. 31(6), 676-687.

Taremian F., Yaghubi H., Pairavi H., Hosseini S. R., Zafar M. ve Moloodi R. (2018). Risk And Protective Factors For Substance Use Among Iranian University Students: A National Study. Substance Abuse Treatment, Prevention and Policy 13(46). 1-9.

Tavolacci M. P., Ladner J., Grigioni S., Richard L., Villet H. ve Dechelotte P. (2013). Prevalence And Association Of Perceived Stress, Substance Use And Behavioral Addictions: A Cross-Sectional Study Among University Students İn France, 2009-2011. BMC Public Health, 13, 724.

Torres C., Otero P., Bustamante B., Blanco V., Díaz O. ve Vázquez F. L. (2017). Mental Health Problems and Related Factors in Ecuadorian College Students. Int. J. Environ. Res. Public Health, 14, 530.

Topkaya N. ve Meydan B. (2013). Üniversite Öğrencilerinin Problem Yaşadıklanı Alanlar, Yardım Kaynakları ve Psikolojik Yardım Alma Niyetleri. Trakya Üniversitesi Eğitim Fakültesi Dergisi, 3(1), 25-37.-

Wallace D. D., Boynton M. H. ve Lytle L. A. (2017). Multilevel Analysis Exploring The Links Between Stress, Depression, And Sleep Problems Among Two-Year College Students. J Am Coll Health. 65(3), 187-196.

Yllmaz E. ve Özkan S. (2007). Üniversite öğrencilerinin beslenme alışkanlıklarının incelenmesi. Firat Sağllk Hizmetleri Dergisi, 2(6), 30-40.

Yi S., Peltzer K., Pengpid S. ve Susilowati I. H. (2017). Prevalence and associated factors of illicit drug use among university students in the association of 
Bir Üniversiteye Bağlı İlçedeki Sağlık Hizmetleri Meslek Yüksekokulunda Okuyan Öğrencilerin Problemlerinin Analizi

Southeast Asian Nations. Substance Abuse Treatment, Prevention, and Policy, 12(9), 1-7.

Kaynakça Bilgisi / Citation Information

Erkuran, H. ve Demirbağ, B. C. (2020). Bir üniversiteye bağl1 ilçedeki sağlık hizmetleri meslek yüksekokulunda okuyan öğrencilerin problemlerinin analizi. OPUS-Uluslararası Toplum Araştırmaları Dergisi, 17(38), 5228-5243. DOI: 10.26466/opus.749235 